other proxy sources, one can possibly surmise that the LIA might have had at best only a weak presence over the Himalayas.

\section{References}

Borgaonkar, H.P., Pant, G.B. and Rupa Kumar, K., 1999 , Tree-ring chronologies from western Himalaya and their dendroclimatic potential, IAWA Journal, 20. 295-307.
Briffa, K.R., Jones, P.D., Bartholin, T.S., Eckstein, D., Schweingruber, F.H., Karlen, W., Zetterberg, P. and Eronen, M., 1992. Fennoscandian summers from AD 500: temperature changes on short and long timescales, Climate Dynamics, 7, 111-119.

Cook, E.R., Krusic, P.J. and Jones, P.D., submitted Dendroclimatic signals in long tree-ring chronologies from the Himalayas of Nepal, Int. J. Climatol.

Hughes, M.K., 1992, Dendroclimatic evidence from the western Himalaya. In: R. S. Bradlay and P. D. Jones (eds.). Climate Since A.D. 1500; 415-431. Routledge, London.
Yadav, R.R., Park, W. a and Bhattacharyya, A 1999 Spring temperature variations in western Himalaya, India, as reconstructed from tree-rings: A.D. 1390-1987. The Holocene, 9, 1; 85-90.

For full references please consult:

www.pages-igbp.org/products/newsletters/ref2002_1.htm

\title{
Fire and Climate History in the Western Americas From Tree Rings
}

\section{Thomas W. Swetnam}

Laboratory of Tree-Ring Research, The University of Arizona, Tucson, Arizona, USA; tswetnam@Itrr.arizona.edu

The usefulness of tree rings in historical climatology derives from their high temporal resolution, exact dating, and sensitivity to precipitation and temperature variables. Another key strength of tree-ring climate proxies is that they can be massively replicated across broadscale networks encompassing regions, continents, and hemispheres. In addition to influencing the growth of trees, climate variations affect ecological processes, and these processes are also recorded within tree rings. One of the most climatically responsive ecological processes is the occurrence and extent of wildfires. The record of past forest fires is often beautifully preserved within tree-ring sequences as "fire scars" on the lower boles of trees (Fig. 1). By extensively sampling fire-scarred trees in numerous locations, dendroecologists are now assembling broad-scale fire-scar chronology networks (Fig. 2) that are approaching the extent and replication of tree-ring width networks that dendroclimatologists have been assembling since the 1960s.

In combination with calibrated precipitation and temperature reconstructions from tree rings, firescar networks help improve our understanding of ecologically-effective climatic change. These records can assist in identifying important changes in regional to global climate patterns, and they can be useful in developing models for forecasting fire hazards in advance of fire seasons. In this brief note I review examples of findings from fire-scar

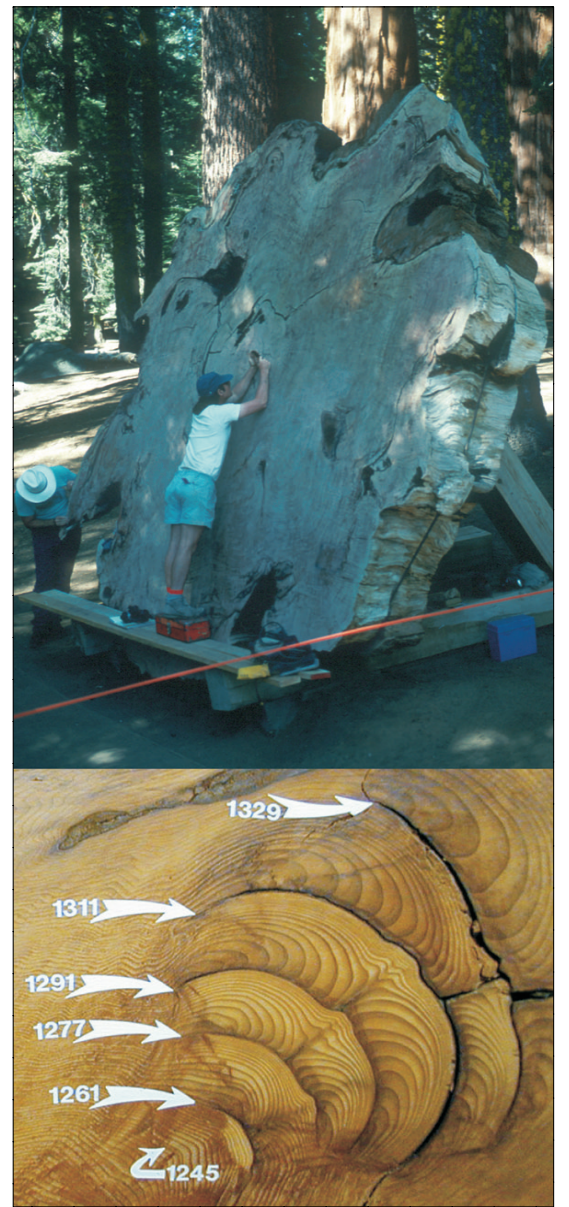

Fig.1: Fire scars are created on the lower boles of trees by surface fires that injure the growing tissue beneath the bark (cambium), but do not kill the tree. Giant sequoias in the Sierra Nevada, California were repeatedly scarred by surface fires over the past three millennia (Swetnam 1993). By examining cross sections from dead trees, such as the one in the upper photo at Sequoia National Park, we can clearly identify fire scars within the ring sequences (lower photo), and date these fires to the year and season of occurrence. This particular tree had an innermost ring date of $256 \mathrm{BC}$, and contained more than 80 different fire-scar dates. Composites of fire-scar chronologies from individual trees, and from forest stands, provide time series reflecting fire occurrence and extent across a range of spatial scales. networks in the western Americas. The fire history research community is just beginning to organize and coordinate at the global scale, and there are many new opportunities to collaborate, exchange data, and to analyze paleofire records from new regions.

\section{Regionally Synchronized Fire Events}

One of the strongest indications that fire-scar chronologies can reflect climatic variations is the occurrence of synchronized fire-scar events in widely scattered locations, from forest stands to regional scales (Fig. 3A). These regional fire events typically coincided with drought years (Fig. 3B). Similar patterns of fire event synchrony and drought are observed in the $20^{\text {th }}$ century. For example, 1988 and 1989 were severe drought years in the western United States, and enormous areas burned during these years (e.g. the 1988 fires in Yellowstone National Park, and many large fires in the Great Basin and Southwest in 1989). Extensive fires occurred at the global-scale in the El Niño years of 1982-83 and 1997-98 in tropical forests of Indonesia, central Mexico, and the Amazon Ba$\sin$.

A combination of modern and paleo time series of fire occurrence and weather indicates that high and low fire extent years were often associated with extreme phases of the ENSO (La Niña and EI Niño). These patterns were not simply ENSO-related droughts causing high fire occurrence, or wet periods 
causing low fire occurrence, but also included inter-seasonal and inter-annual lagging patterns. For example, a common finding in the Rocky Mountains of Colorado, Arizona and New Mexico, in the Sierra Nevada of California, northern Mexico, and Patagonia and in Argentina was that the most extensive fire years tended to be dry years following 2 or 3 wet years (Fig. 3C). Moreover, the smallest fire years tended to be wet years that followed a dry year. These lagging relations occurred primarily in semi-arid woodlands and forests, and were most likely due to the importance of growth and accumulation of fine fuels (i.e. grasses and tree needles). Wet conditions in prior years were necessary for sufficient accumulation of fine fuels to carry surface fires in these open forests with widely spaced trees.

Combined with improved interseasonal climate forecasting based on ENSO conditions, these lagging patterns hold promise for developing useful fire hazard forecasting models. Fire managers could use these forecasts to position additional fire-fighting resources in advance of bad fire seasons, or to plan for conducting more "prescribed burns" during less hazardous seasons. These kinds of forecasting tools are currently in development and testing in the western and southern United States, where ENSO teleconnections are particularly important to seasonal precipitation amounts. Additional studies of paleofire records will be useful to identify the changing strength and consistency of ENSO-fire teleconnections, both spatially and temporally.

\section{Inter-Regional Comparisons of Fire and Climate}

An exciting research opportunity in paleofire climatology is the assembly and comparison of regional fire histories along the PEP-1 transect (Pole-to-Equator-to-Pole) in the western Americans (Fig. 2). We know that ENSO has important effects on seasonal precipitation and temperature along this transect, and these teleconnections are inverse between some regions. For example, rainfall amounts in the Pacific Northwest and northern Rocky Mountains of North America are usually opposite in response to El Niño and La Niña events relative to the southwestern and southeastern United States (e.g. EI Niño events are dry in the NW and wet in the SW and SE). Recent studies have shown that paleofire records tend to follow these patterns: extensive fire events in Oregon tended to correspond with the EI Niño phase of ENSO (Heyerdahl et al. in press), while extensive fire events in Arizona and New Mexico tended to correspond with La Niña events (Swetnam and Betancourt 1998).

Because ENSO, the Pacific Decadal Oscillation (PDO) and other broadscale ocean-atmosphere patterns modulate precipitation and temperature variations at regional to inter-hemispheric scales, we should expect that fire activity would be synchronized at similar scales. Indeed, in an inter-hemispheric comparison of fire-scar chronologies (Kitzberger et al. 2001), we found that fire activity in the southwestern United States was synchronous with fire activity in Patagonia Argentina from circa AD 1700 to 1900 . Precipitation regimes in these two regions are affected in similar ways by ENSO. Not only were the two regional fire chronologies coherent within the ENSO frequency band (i.e. 2 to 7 years), we noted a similar decadal-scale secular change in the two fire-scar time series from circa 1780-1830. These are low fire frequency decades, and they coincided with an exceptionally cold period in both hemispheres (e.g. see the Mann et al. (1999) temperature reconstruction for the northern hemisphere). Moreover, this period had a markedly reduced frequency and amplitude of ENSO events, as indicated in tree-ring width, coral and ice core isotopic reconstructions (Kitzberger et al. 2001). In another study, using a fire-scar network from giant sequoia groves in the Sierra Nevada of California, we found that decadal fluctuations in temperatures were correlated with fire frequencies

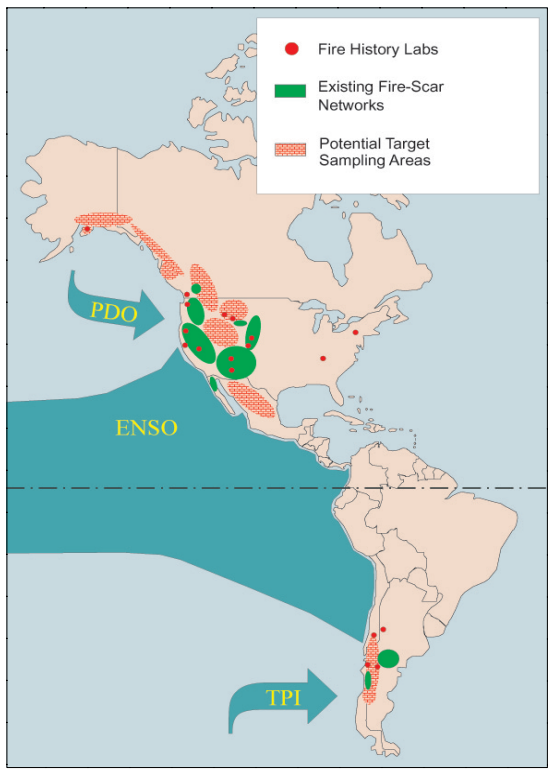

Fig. 2: Map of the Americas with current and potential sampling areas for fire-scar networks on the western side of the continents. Targeting locations with likely responses to ENSO (EI Niño-Southern Oscillation), PDO (Pacific Decadal Oscillation), and TansPolar Index) variations will provide opportunities for inter-regional and inter-hemispheric comparisons. Locations of laboratories and individual scientists currently developing crossdated fire-scar chronologies in the western Americas are also shown.

over the past 2,000 years (Swetnam 1993).

\section{New Fire-Scar Chronology Networks and Multi-Proxy Fire Histories}

These encouraging results indicate that there is high potential to use fire-scar networks to evaluate interannual to decadal-scale climate variability. We are at an early stage in the development of regional paleofire networks, and there is a need for new collections in unsampled regions where interesting climatic teleconnections are expected. For example, networks of crossdated fire-scar chronologies are needed from British Columbia and southeastern Alaska, the Great Basin, and from additional regions in Chile and Argentina. Development of fire-scar chronology networks in the subtropics and tropics of Mexico, Brazil, Peru, and other countries will be challenging because annual tree rings are difficult to discern in many of the tree species in these regions. Nevertheless, an effective strategy might focus on sampling in high mountain areas, and regions with seasonal- 

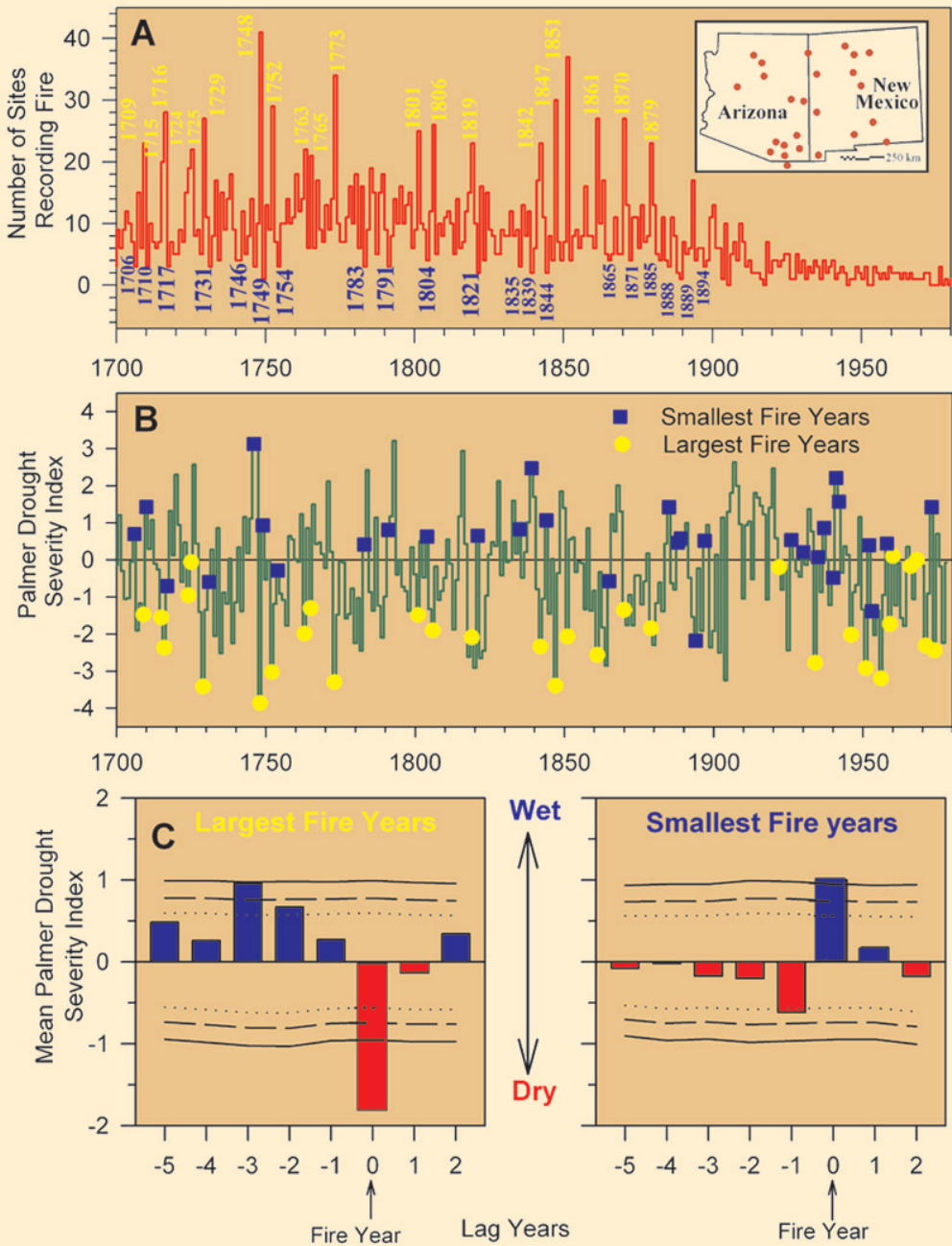

Fig. 3: A: Fire-scar chronology from the Southwestern United States (Arizona and New Mexico, see inset map). This time series shows the number of sites recording fire-scar events each year from $A D 1700$ to 1980. A total of 63 fire-scar chronologies were composited from 25 mountain ranges (red dots on inset map) for this time series. The largest fire years are labeled in yellow, and the smallest fire years are labeled in blue. The lack of regional fire events after circa 1900 was due to the disruption of surface fire regimes by intensive livestock grazing, and organized fire suppression by government agencies. B: Time series of June-July-August Palmer Drought Severity Index (PDSI) from grid-point tree-ring reconstructions (Cook et al. 1999, locations of grid points are dots on inset map in A). The largest fire years (yellow dots) and smallest fire years (blue squares) are superimposed on the PDSI time series. The 1700 to 1900 largest and smallest fire years are from the regional fire-scar time series (in B), and the 1900 to 1980 largest and smallest years are from a time series of annual area burned from National Forests in Arizona and New Mexico. $\boldsymbol{C}$ : Results of superposed epoch analyses, where the mean PDSI values were computed for the twenty largest and twenty smallest fire years from 1700 to 1900, and previous 5 years and subsequent 2 years (lag years). The horizontal lines show the 90\%, 95\%, and 99\% confidence intervals computed from a Monte Carlo resampling procedure. Note that largest fire years were very dry, with wet years preceding, and vice versa for smallest fire years (see Swetnam and Betancourt 1998).

ly variable rainfall patterns and fire regimes.

Assembly of many, well-dated fire-scar chronologies from multiple locations is a key to identifying fireclimate patterns. This will require sustained efforts and coordinated data sharing among investigators and laboratories. Educational exchange and financial support is needed to assist in developing new laboratories and trained paleofire dendrochronologists. There should be opportunities to do this by coordinating efforts with other tree-ring initiatives, such as the PEP-I, InterAmerican-Institute tree-line dendrochronology project (see Luckman and Boninsegna, PAGES News 9(3) :17-19, Dec. 2001).
Another promising area of investigation is the linking of the tree-ring paleofire records with sedimentary charcoal records. When sampled from the same watersheds and drainage basins, or when the sedimentary records have high temporal resolution (e.g. varves, or fine interval sampling and ${ }^{210} \mathrm{~Pb}$ dating), there may be opportunities to crossdate fire events between tree-ring and sediment-charcoal time series. This kind of multiproxy approach could be very useful in distinguishing local versus regional fire events. Combined with pollen time series from the same areas, coordinated tree-ring/ sedimentary charcoal studies could provide new insights on the multiple scales of climatic change, fire regime and vegetative responses spanning years to millennia, and local areas to regions.

Paleofire climatology has great potential to improve our understanding of the effects of past climate variations - especially those variations relevant to ecosystem change. Other indirect climate proxies, such as lake levels and glacier fluctuations are commonly cited as corroborating evidence in support of climate reconstructions from tree rings, corals, and ice cores. It is now clear that paleofire time series are of similar and increasing utility as an independent measure of ecologically-effective climate change.

\section{REFERENCES}

Heyerdahl, E. K., Brubaker, L. B. and Agee, J. K., in press, Annual and decadal influence of climate on fire regimes (1687-1994) of the Blue Mountains, USA. The Holocene.

Kitzberger,T., Swetnam, T.W. and Veblen, T.T., 2001, Inter-hemispheric synchrony of forest fires and the El Nino-Southern Oscillation, Global Ecology and Biogeography ,10, 315-326.

Cook, E. R., Meko, D. M. Stahle, D. W and Cleaveland, M. K., 1999, Drought reconstructions for the continental United States, Journal of Climate, 12, 1145-1162.

Swetnam, T.W., 1993, Fire history and climate change in giant sequoia groves, Science, 262, 885-889.

For full references please consult:

www.pages-igbp.org/products/newsletters/ref2002_1.html 